\title{
Genetic pathogenesis of immunoglobulin light chain amyloidosis: basic characteristics and clinical applications
}

Linchun $\mathrm{Xu}^{1,2}$ and Yongzhong $\mathrm{Su}^{3^{*}}$

\begin{abstract}
Immunoglobulin light chain amyloidosis (AL) is an indolent plasma cell disorder characterized by free immunoglobulin light chain (FLC) misfolding and amyloid fibril deposition. The cytogenetic pattern of AL shows profound similarity with that of other plasma cell disorders but harbors distinct features. AL can be classified into two primary subtypes: non-hyperdiploidy and hyperdiploidy. Non-hyperdiploidy usually involves immunoglobulin heavy chain translocations, and $t(11 ; 14)$ is the hallmark of this disease. $T(11 ; 14)$ is associated with low plasma cell count but high FLC level and displays distinct response outcomes to different treatment modalities. Hyperdiploidy is associated with plasmacytosis and subclone formation, and it generally confers a neutral or inferior prognostic outcome. Other chromosome abnormalities and driver gene mutations are considered as secondary cytogenetic aberrations that occur during disease evolution. These genetic aberrations contribute to the proliferation of plasma cells, which secrete excess FLC for amyloid deposition. Other genetic factors, such as specific usage of immunoglobulin light chain germline genes and light chain somatic mutations, also play an essential role in amyloid fibril deposition in AL. This paper will propose a framework of AL classification based on genetic aberrations and discuss the amyloid formation of AL from a genetic aspect.
\end{abstract}

Keywords: Immunoglobulin light chain amyloidosis, Genetic aberrations, Prognosis, Therapy

\section{Background}

Immunoglobulin light chain amyloidosis (AL) is an indolent plasma cell disorder characterized by the misfolding of free light chains (FLC) and amyloid fibril deposition in different tissues [1]. The annual incidence of this disease is around ten affected individuals per million people [2-4]. The clinical presentations of AL are various and not specific, making the disease diagnosis difficult and delay most of the time. Theoretically, any organ can be involved, except the brain, with the heart being the most commonly involved organ, followed by the kidney,

\footnotetext{
*Correspondence: suyzst@126.com

${ }^{3}$ Department of Hematology, The First Affiliated Hospital of Shantou University Medical College, Shantou 515041, Guangdong, China Full list of author information is available at the end of the article
}

liver, gastrointestinal tract, soft tissue, and peripheral and autonomic neural systems [1, 5-7] (see Fig. 1). Among these, the heart has the most significant prognostic impact [8].

Plasma cells in $\mathrm{AL}$ are usually indolent, but $\mathrm{AL}$ is regarded as a dangerous disease because only about $20 \%$ of patients could survive over 10 years, and about $25 \%$ of patients would die within the first 6 months mainly due to related organ complications [9-11].

In the past decades, significant progress has been made in understanding the molecular and genetic pathogenesis of AL. Concepts of precise treatments based on the disease's genetic properties have emerged, which hopefully would lead to a new era of therapies in the future. This review article will focus on the pathogenesis, clinical features, and prognostic impacts of different genetic original author(s) and the source, provide a link to the Creative Commons licence, and indicate if changes were made. The images or other third party material in this article are included in the article's Creative Commons licence, unless indicated otherwise in a credit line to the material. If material is not included in the article's Creative Commons licence and your intended use is not permitted by statutory regulation or exceeds the permitted use, you will need to obtain permission directly from the copyright holder. To view a copy of this licence, visit http://creativecommons.org/licenses/by/4.0/. The Creative Commons Public Domain Dedication waiver (http://creativeco mmons.org/publicdomain/zero/1.0/) applies to the data made available in this article, unless otherwise stated in a credit line to the data. 


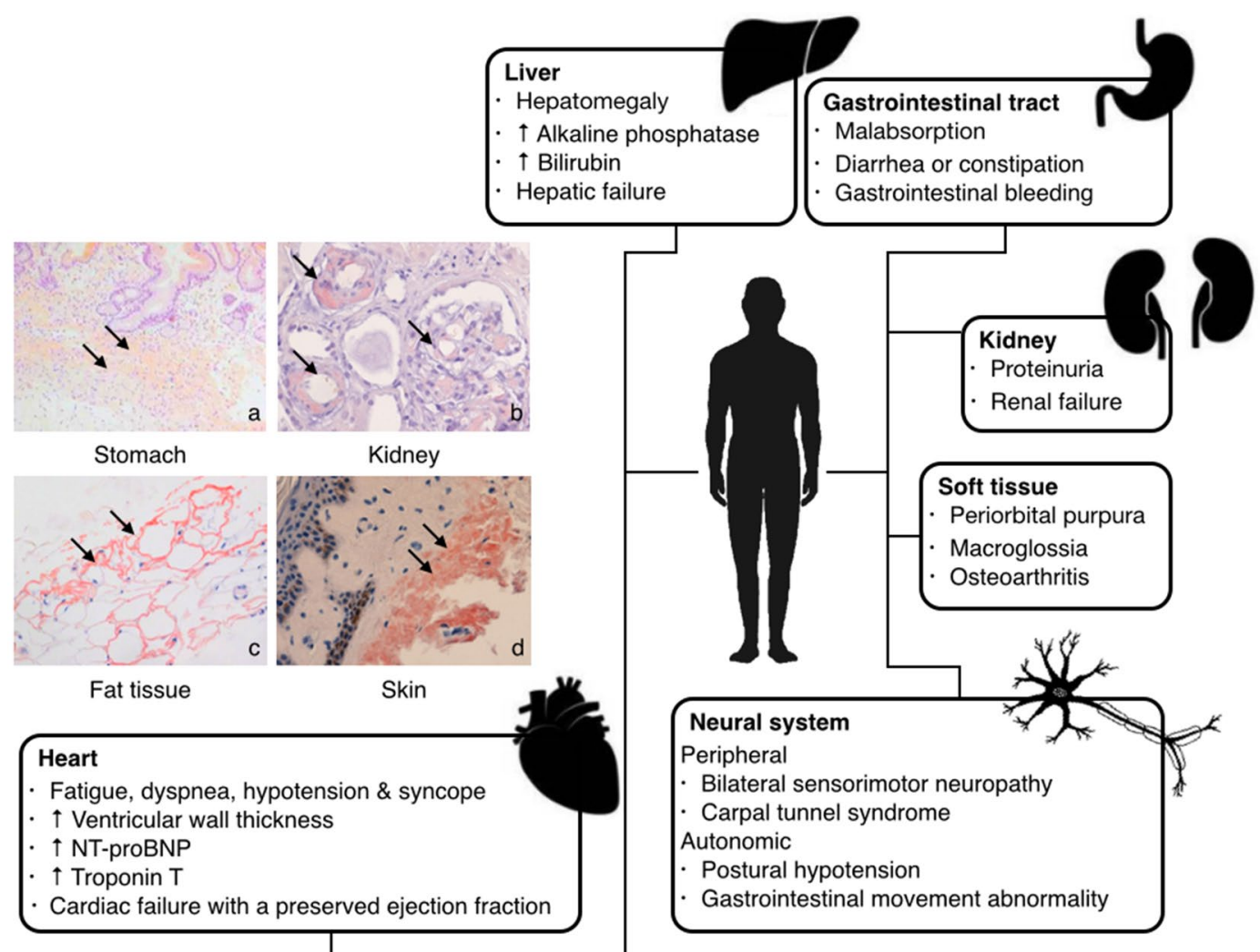

Fig. 1 Clinical presentations and representative biopsy samples of AL amyloidosis. Free light chains secreted by the clonal plasma cells deposit in various tissues, including the heart, kidney, liver, gastrointestinal tract, soft tissues and neural systems. Detailed information about each involved organ is summarized in the figure. The representative biopsy samples of the stomach (a), kidney (b), fat tissue (c) and skin (d) stained with Congo red show amyloid deposition in these tissues, indicated with arrows (a was derived from Li Tian et al. [7], and b-d were from Ting Li et al. with permission [6])

aberrations present in AL. We will also briefly discuss the influences of specific usages of germline genes and mutations on the immunoglobulin gene in amyloid formation.

\section{The cytogenetic landscape of AL amyloidosis}

The cytogenetic landscape of AL has profound similarity with that of monoclonal gammopathy of undetermined significance (MGUS) and multiple myeloma (MM). Several studies have indicated that the cytogenetic concepts applied in MM may be transferable to AL.

MM can be classified into two distinct genetic branches: non-hyperdiploidy and hyperdiploidy based on chromosome contents, and they can further form various subclones through secondary mutations [12-14]. Similar to this, non-hyperdiploidy, which mainly involves immunoglobulin heavy chain (IgH) locus translocation, and hyperdiploidy are recognized to be the two primary clones in $\mathrm{AL}$, whereas other chromosome aberrations and point mutations are frequently associated with subclone formation during disease evolution.
Patients with AL also show a high frequency of chromosome instability like other plasma cell disorders. Data shows that $60-90 \%$ of AL patients harbor at least one chromosome abnormalities and about $50-70 \%$ of them have translocations involving the IgH locus on chromosome 14 [15-17].

However, although AL shares some similar genetic features with other plasma cell dyscrasia, its distribution patterns of the cytogenetic abnormalities differ significantly from that of MGUS and MM. In AL, $t(11,14)$ is the most common genetic abnormality with a frequency ranging from 40 to $60 \%[15,18]$, while it only contributes to less than $20 \%$ of the cytogenetic abnormalities in MGUS and MM [12]. Meanwhile, the frequency of hyperdiploidy and secondary genetic mutations in AL seems to be lower than that of other plasma cell dyscrasia $[15,18]$.

Unlike other plasma cell dyscrasia, of which the prognostic roles of different genetic aberrations have been better described, less is known in AL. However, there is an increasing number of studies about this topic. Most 
researches about AL detected chromosome aberrations through the interphase-fluorescence in situ hybridization (iFISH) technique, using the genetic probes in MM. Different genetic aberrations involve different pathways of pathogenesis and influence prognostic outcomes and decision-making in clinical practice. The following section will focus on the basic characteristics and clinical features of the major genetic aberrations present in AL.

\section{Normal chromosome profile}

About $10-40 \%$ of AL patients cannot be detected to harbor any chromosome aberration by the MM's genetic probes. This patient group tends to have lower plasma cell burden, less severe cardiac involvement, longer progression-free survival (PFS) and overall survival (OS) [15-17, 19], indicating that the absence of chromosome aberration in AL may be a favorable prognostic predictor of outcome.

\section{Immunoglobulin heavy chain translocation}

IgH translocation is the most common abnormal cytogenetic event in AL. This translocation involves the juxtaposition of different chromosomes to the IgH locus on chromosome 14, which leads to the overexpression or dysregulations of various genes, especially the cyclin gene families [12, 20-23]. In MM, $t(11 ; 14), t(4 ; 14)$ and $t(14 ; 16)$ are the three most common IgH translocations, and $t(4 ; 14)$ together with $t(14 ; 16)$ are classified as the highrisk genetic factors [12, 24], whereas in $\mathrm{AL}$, their prognostic impacts are less well defined.

\section{$t(11 ; 14)$}

Translocation $\mathrm{t}(11 ; 14)(\mathrm{q} 13 ; \mathrm{q} 32)$ is the most prevalent genetic aberration present in AL. This translocation involves the juxtaposition of the IgH locus on chromosome 14 to the oncogene cyclin D1 (CCND1) on chromosome 11, leading to the overexpression of CCND1 in plasma cells $[20,25]$.

Translocation $t(11 ; 14)$ is usually genetically stable with a low rate of subclone formation and progression both in AL and non-AL plasma cell disorders [26]. Probably for this reason, $t(11 ; 14)$ is recognized as a neutral or favorable prognostic factor in MM [13]. However, this rule seems not to be transferable to AL. A study including 401 AL patients reported that patients harboring $t(11 ; 14)$ had inferior survival outcomes when their plasma cell burden was less than $10 \%$ [15]. Another study also demonstrated that the risk of death in patients with $t(11 ; 14)$ was 2.1 (confidence interval 1.04-6.4) [27].

Patients with $\mathrm{t}(11 ; 14)$ are associated with low plasma cell clones in the bone marrow, but they tend to be loaded with a heavy FLC burden in the serum, which is shown to be related to shorter survival in several studies
[28-30]. The elevated light chain level may increase the availability and tendency of the light chain precursor for amyloid fibril formation in different organs, especially the heart, which may in part explain the more unsatisfactory survival outcome in this patient group.

Reasons for the higher free light chain level in $t(11 ; 14)$ compared to that in non-t $(11 ; 14)$ remain poorly understood, but the IgH locus translocation that leads to the disruption of the IgH expression or structure may partially explain that. This is supported by the evidence from a study that identified a strong relationship between $t(11 ; 14)$ and the lack of an intact immunoglobulin in AL patients [31]. Data from a MM study also showed that IgH locus translocation could lead to a higher FLC ratio and higher FLC level [29]. These studies indicate that the disruption of the IgH expression or structure, probably caused by IgH translocation, can result in lower intact immunoglobulin but higher FLC level. Another article demonstrated that the elevated level of CCND1 in plasma cells was associated with more FLCs but fewer intact M-proteins, and it was an independent predictor of survival in AL patients. However, the authors did not perform the iFISH analysis in the research [32]. Since $t(11 ; 14)$ can lead to a high CCND1 level, whether it is the CCND1 itself, the translocation of the IgH locus, or some other reason that results in low intact immunoglobulin but high FLC production remains elusive.

The prognostic effect of $t(11 ; 14)$ in AL patients is still controversial, and treatment options seem to have a significant impact on the clinical outcomes of this patient group (see Table 1). Bochtler et al. first reported in 2015 that $t(11 ; 14)$ was associated with an inferior outcome in patients treated with bortezomib-based regimens in a study with 101 patients [33]. Further study results from other research centers also support Bochtler's finding, indicating that patients with $\mathrm{t}(11 ; 14)$ have a lower response rate and shorter median OS time when receiving bortezomib-based regimens as first-line therapy [18, 34]. However, these results should still be interpreted with caution since they are retrospective. A study also indicates that the adverse prognostic impact of $t(11 ; 14)$ may only restrict to the patient group with favorable factors such as younger age, less organ involvement, and Mayo stage I/II [18]. In other words, in a patient with unfavorable clinical features, the presence of $t(11 ; 14)$ may not have additional adverse effects.

On the other hand, in contrast to bortezomib, melphalan shows a potential to overcome the adverse effect of $t(11 ; 14)$. In patients receiving melphalan/dexamethasone as first-line therapy, a tendency of longer OS was observed in those with $\mathrm{t}(11 ; 14)$ compared with those without $t(11 ; 14)[35]$. Besides, patients with $t(11 ; 14)$ also benefit from high-dose melphalan (HDM) chemotherapy 
Table 1 Hematologic response and survival outcome of different treatment modalities in AL amyloidosis with different genetic aberrations

\begin{tabular}{|c|c|c|c|c|c|c|c|c|c|}
\hline \multirow{2}{*}{$\begin{array}{l}\text { Treatment } \\
\text { modalities }\end{array}$} & \multirow[t]{2}{*}{ Arm 1} & \multirow[t]{2}{*}{ Arm 2} & \multirow{2}{*}{$\begin{array}{l}\text { Patient } \\
\text { number } \\
\text { (n1/n2) }\end{array}$} & \multicolumn{3}{|c|}{ Hematologic response } & \multicolumn{3}{|c|}{ Survival outcome } \\
\hline & & & & $\begin{array}{l}\text { End point } \\
1\end{array}$ & Arm 1/Arm 2 & $\begin{array}{l}P \\
\text { value }^{c}\end{array}$ & $\begin{array}{l}\text { End point } \\
2\end{array}$ & Arm 1/Arm 2 & $\begin{array}{l}P \\
\text { value }\end{array}$ \\
\hline $\begin{array}{l}\text { Bortezomib- } \\
\text { based [34] }\end{array}$ & $t(11 ; 14)$ & Non- $(11 ; 14)$ & $44 / 91$ & $\geq V G P R$ & $41 \% / 66 \%$ & $<0.01$ & 5-year OS & $46 \% / 72 \%$ & 0.026 \\
\hline $\begin{array}{l}\text { Bortezomib- } \\
\text { based [33] }\end{array}$ & $t(11 ; 14)$ & Non- $(11 ; 14)$ & $64 / 37$ & $\geq V G P R$ & $23 \% / 47 \%$ & 0.02 & Median OS & 8.7 months/40.7 months & 0.05 \\
\hline $\begin{array}{l}\text { Bortezomib- } \\
\text { based [18] }\end{array}$ & $t(11 ; 14)$ & Non-(11;14) & $82 / 89$ & $\geq V G P R$ & $52 \% / 77 \%$ & 0.004 & Median OS & 15.0 months/27.0 months & 0.05 \\
\hline $\begin{array}{l}\text { Bortezomib- } \\
\text { based [18] }\end{array}$ & Trisomies & $\begin{array}{l}\text { Non triso- } \\
\text { mies }\end{array}$ & $45 / 125$ & $\geq V G P R$ & $72 \% / 65 \%$ & 0.46 & Median OS & 14.0 months/38.0 months & 0.08 \\
\hline $\begin{array}{l}\text { Bortezomib- } \\
\text { based [33] }\end{array}$ & $\begin{array}{l}\text { High risk } \\
\text { aberrations }^{\mathrm{a}}\end{array}$ & $\begin{array}{l}\text { Non-high } \\
\text { risk aber- } \\
\text { rations }\end{array}$ & $13 / 85$ & $\geq V G P R$ & $67 \% / 26 \%$ & 0.008 & Median OS & NR/10.6 months & 0.04 \\
\hline $\mathrm{MD}[35]$ & $t(11 ; 14)$ & Non- $(11 ; 14)$ & $61 / 42$ & $\geq V G P R$ & $18 \% / 22 \%$ & 0.60 & Median OS & 38.2 months/17.5 months & 0.21 \\
\hline $\mathrm{MD}[35]$ & Gain of 1q21 & $\begin{array}{l}\text { Non gain of } \\
1 \text { q21 }\end{array}$ & $23 / 77$ & $\geq \mathrm{VGPR}$ & $5 \% / 25 \%$ & 0.06 & Median OS & 12.5 months/38.2 months & 0.002 \\
\hline $\mathrm{MD}[35]$ & Del13q14 & $\begin{array}{l}\text { Non } \\
\text { del13q14 }\end{array}$ & $36 / 66$ & $\geq V G P R$ & $23 \% / 18 \%$ & 0.78 & 5 -year OS & $36 \% / 33 \%$ & 0.70 \\
\hline $\mathrm{MD}[35]$ & $\begin{array}{l}\text { Hyperdip- } \\
\text { loidy }^{\mathrm{b}}\end{array}$ & $\begin{array}{l}\text { Non-hyper- } \\
\text { diploidy }\end{array}$ & $15 / 84$ & $\geq V G P R$ & $10 \% / 22 \%$ & 1 & 5-year OS & $40 \% / 36 \%$ & 0.70 \\
\hline $\begin{array}{l}\text { Melphalan- } \\
\text { based [18] }\end{array}$ & $t(11 ; 14)$ & Non- $(11 ; 14)$ & $96 / 95$ & $\geq V G P R$ & $41 \% / 54 \%$ & 0.13 & Median OS & 23.0 months/26.0 months & 0.94 \\
\hline $\begin{array}{l}\text { Melphalan- } \\
\text { based [18] }\end{array}$ & Trisomies & $\begin{array}{l}\text { Non triso- } \\
\text { mies }\end{array}$ & $49 / 139$ & $\geq V G P R$ & $39 \% / 52 \%$ & 0.2 & Median OS & 15.0 months/32.0 months & 0.02 \\
\hline $\begin{array}{l}\mathrm{HDM}+\mathrm{ASCT} \\
{[36]}\end{array}$ & $t(11 ; 14)$ & Non- $(11 ; 14)$ & $72 / 51$ & $C R$ & $41 \% / 20 \%$ & 0.02 & Median OS & NR/93.7 months & 0.07 \\
\hline $\begin{array}{l}\mathrm{HDM}+\mathrm{ASCT} \\
{[36]}\end{array}$ & Gain of 1q21 & $\begin{array}{l}\text { Non gain of } \\
1 \mathrm{q} 21\end{array}$ & $25 / 91$ & $C R$ & $22 \% / 35 \%$ & 0.32 & Median OS & NR/128.8 months & 0.93 \\
\hline $\begin{array}{l}\mathrm{HDM}+\mathrm{ASCT} \\
{[36]}\end{array}$ & Del13q14 & $\begin{array}{l}\text { Non } \\
\text { del13q14 }\end{array}$ & $36 / 87$ & $C R$ & $21 \% / 37 \%$ & 0.13 & Median OS & 128.8 months/NR & 0.10 \\
\hline $\begin{array}{l}\mathrm{HDM}+\mathrm{ASCT} \\
{[36]}\end{array}$ & $\begin{array}{l}\text { Hyperdip- } \\
\text { loidy }^{\mathrm{b}}\end{array}$ & $\begin{array}{l}\text { Non-hyper- } \\
\text { diploidy }\end{array}$ & $16 / 95$ & $C R$ & $27 \% / 33 \%$ & 0.77 & Median OS & 90.6 months/128.8 months & 0.84 \\
\hline $\begin{array}{l}\mathrm{HDM}+\mathrm{ASCT} \\
{[36]}\end{array}$ & $\begin{array}{l}\text { High risk } \\
\text { aberrations }^{\mathrm{a}}\end{array}$ & $\begin{array}{l}\text { Non high } \\
\text { risk aber- } \\
\text { rations }\end{array}$ & $9 / 113$ & $C R$ & $0 \% / 35.2 \%$ & 0.03 & Median OS & 47.4 months/NR & 0.06 \\
\hline ASCT [18] & $t(11 ; 14)$ & Non- $(11 ; 14)$ & $134 / 113$ & $\geq V G P R$ & $70 \% / 78 \%$ & 0.15 & Median OS & NR/NR & 0.51 \\
\hline ASCT [18] & Trisomies & $\begin{array}{l}\text { Non triso- } \\
\text { mies }\end{array}$ & $56 / 186$ & $\geq V G P R$ & $80 \% / 71 \%$ & 0.17 & Median OS & NR/NR & 0.98 \\
\hline $\mathrm{DD}[30]$ & $t(11 ; 14)$ & Non- $(11 ; 14)$ & $53 / 32$ & $\begin{array}{l}\text { Median } \\
\text { hemEFS }\end{array}$ & 24.3 months $/ 5.5$ months & $<0.01$ & Median OS & NR/19.3 months & 0.07 \\
\hline $\mathrm{DD}[30]$ & Gain of 1q21 & $\begin{array}{l}\text { Non gain of } \\
1 \mathrm{q} 21\end{array}$ & $25 / 58$ & $\begin{array}{l}\text { Median } \\
\text { hemEFS }\end{array}$ & 5.8 months/21.6 months & 0.03 & Median OS & 14.8 months/NR & 0.02 \\
\hline DVD [30] & $t(11 ; 14)$ & Non- $(11 ; 14)$ & $23 / 20$ & $\begin{array}{l}\text { Median } \\
\text { hemEFS }\end{array}$ & 19.0 months/10.0 months & 0.69 & Median OS & NR/NR & 0.62 \\
\hline DVD [30] & Gain of 1q21 & $\begin{array}{c}\text { Non gain of } \\
1 \text { q21 }\end{array}$ & $10 / 30$ & $\begin{array}{l}\text { Median } \\
\text { hemEFS }\end{array}$ & 6.8 months/ 22.1 months & 0.11 & Median OS & 9.5 months/NR & 0.02 \\
\hline DRD [66] & $t(11 ; 14)$ & Non- $(11 ; 14)$ & $16 / 15$ & $\begin{array}{l}\text { Median } \\
\text { hemEFS }\end{array}$ & 17.3 months/22.6 months & $>0.05$ & - & & \\
\hline DRD [66] & Gain of 1q21 & $\begin{array}{c}\text { Non gain of } \\
1 \text { q21 }\end{array}$ & $16 / 15$ & $\begin{array}{l}\text { Median } \\
\text { hemEFS }\end{array}$ & 10.9 months/NR & $<0.01$ & - & & \\
\hline $\begin{array}{l}\text { IMiD-based } \\
\text { [18] }\end{array}$ & $t(11 ; 14)$ & Non- $(11 ; 14)$ & $8 / 15$ & $\geq V G P R$ & $13 \% / 54 \%$ & 0.04 & Median OS & 12 months/32 months & 0.05 \\
\hline $\begin{array}{l}\text { IMiD-based } \\
\text { [18] }\end{array}$ & Trisomies & $\begin{array}{l}\text { Non triso- } \\
\text { mies }\end{array}$ & $7 / 17$ & $\geq$ VGPR & $40 \% / 38 \%$ & 0.92 & Median OS & 17 months/23 months & 0.93 \\
\hline $\begin{array}{l}\text { Venetoclax } \\
\text { [44] }\end{array}$ & $t(11 ; 14)$ & Non- $(11 ; 14)$ & $31 / 11$ & $\geq V G P R$ & $78 \% / 30 \%$ & 0.02 & Median OS & $\mathrm{NR} / \mathrm{NR}$ & 0.14 \\
\hline
\end{tabular}


Table 1 (continued)

$M D$ Melphalan/dexamethasone, HDM high-dose melphalan, $A S C T$ autologous stem cell transplantation, $D D$ daratumumab/dexamethasone, $D V D$ daratumumab/ bortezomib/dexamethasone, IMiD immunomodulatory drugs, $D R D$ daratumumab/lenalidomide/dexamethasone, VGPR very good partial response, $C R$ complete response, hemEFS hematologic event-free survival, OS overall survival, PFS progression-free survival, NR not reached

${ }^{a}$ High risk aberrations include $t(4 ; 14), t(14 ; 16)$ and del17p13

${ }^{\mathrm{b}}$ Using Wuilleme's criteria. $\geq V G P R=V G P R+C R$

${ }^{c} P$ values $\leqq 0.05$ are highlighted in bold

followed by autologous stem cell transplantation (ASCT), having a significantly higher response rate, hematological event-free survival (hemEFS) as well as a tendency of longer OS. In multivariate analysis, $t(11 ; 14)$ is identified as a favorable prognostic factor regarding hemEFS in HMD + ASCT therapy [36]. The mechanism behind the contradictory effects of bortezomib and melphalan-based regimens is unknown, but these findings point out the importance of carrying out the iFISH analysis to identify the underlying chromosome abnormalities and guide treatment decisions.

Selective AL patients with $t(11 ; 14)$ also respond well to bcl-2 inhibitor, venetoclax. $\mathrm{Bcl}-2$ is a protein that regulates the programmed cell death pathway in normal cells. Cells overloaded with bcl-2 fail to undergo apoptosis but accumulate in the body. Plasma cell disorders, including $\mathrm{MM}$ and $\mathrm{AL}$, especially those with $\mathrm{t}(11 ; 14)$, are associated with the overexpression of bcl-2 [37-39]. The first case report about the efficacy of venetoclax on AL comes from Leung et al., demonstrating that venetoclax could induce a complete response in a patient with $t(11 ; 14)$ plateaued on the standard bortezomib + cyclophosphamide + dexamethasone regimen [40]. Further findings also confirm that the addition of venetoclax could lead to deeper hematological and organ response in a relatively short period [41-44], even in patients without $t(11 ; 14)$ [42]. A recent retrospective study involving 43 patients with relapsed/refractory $\mathrm{AL}$ demonstrates that venetoclax can achieve a VGPR/CR rate of $63 \%$ in total, and the presence of $t(11 ; 14)$ predicts longer PFS compared to non-t $(11 ; 14)$ [44]. However, attention should be paid to the increased risk of infection in venetoclax-based therapies, and the usage of prophylactic antibiotics and intravenous immunoglobulin is recommended [42, 44].

Daratumumab, a monoclonal CD38 antibody, has also shown promise outcome in $t(11 ; 14)$-positive patients as a salvage therapeutic modality, demonstrating a longer hemEFS [30]. This may be explained by the higher CD38 expression level in patients with $t(11 ; 14)$ [45], which can promote the antibody-dependent cytotoxicity effect of daratumumab [46].

In summary, $\mathrm{t}(11 ; 14)$ is associated with an increased FLC level in AL and poorer survival outcomes under bortezomib-based regimens, especially in low-risk patients. Melphalan and novel agents, including venetoclax and daratumumab, may be capable of overcoming the adverse effect of $t(11 ; 14)$ in AL treatments.

\section{$\mathbf{t}(4 ; 14)$}

Translocation $\mathrm{t}(4 ; 14)(\mathrm{p} 16.3 ; \mathrm{q} 32)$ results in the dysregulation of two genes on chromosome 4, the fibroblast growth factor receptor 3 (FGFR3) and multiple myeloma SET domain (MMSET), together with the formation of IGH/MMSET hybrid transcripts [47-49]. This translocation contributes to about $20 \%$ of the genetic abnormalities in MM and is regarded as a poor prognostic factor [50]. Different from MM, $t(4 ; 14)$ comprises only about $2 \%$ of chromosome abnormalities of AL detected by iFISH method [15], but a rate of $14 \%(6 / 42)$ was reported in a study using the reverse transcriptase-polymerase chain reaction to detect the IGH/MMSET transcripts [51]. Due to the rare entity of the AL itself and the low prevalence of $t(4 ; 14)$, data regarding the clinical feature and prognostic effect of $t(4 ; 14)$ in AL are scarce. In bortezomib-based regimens, no adverse prognosis effect was detected in $\mathrm{t}(4 ; 14)$, suggesting that bortezomib-based regimens should be considered in this patient group as in MM [13]. Another study observing the effect of high-risk cytogenetic aberrations including $t(4 ; 14), t(14 ; 16)$ and deletion of $17 \mathrm{p} 13$ in ASCT indicates that these aberrations may confer an unfavorable prognosis [36]. However, the sample sizes in these studies are small, and large-scale studies are needed to confirm these findings.

\section{$t(14 ; 16)$}

Translocation $\mathrm{t}(14 ; 16)(\mathrm{q} 32 ; \mathrm{q} 23)$ has been described in about $2 \%$ of AL, a frequency slightly lower than that of MM ( 5\%) [12, 27]. This translocation leads to the rearrangement of the $M A F$ gene, which encodes a transcription factor binding to CCND2 [13]. A close relationship between increased FLC and IgH translocation, especially $t(14 ; 16)$ is observed in a MM study [29]. Whether AL patients with $t(14 ; 16)$ have an elevated FLC level and an increased predisposition to amyloid fibril formation remains poorly understood. Two studies conducted by Bochtler et al. detected an adverse impact of $t(14 ; 16)$ on AL patients undergoing ASCT with melphalan but not on patients receiving bortezomib-based regimens [33, 
36], but the patients numbers were small to reach a definitive conclusion.

\section{Other IgH locus translocations}

Other IgH locus translocations, such as $\mathrm{t}(14 ; 20)$ and $\mathrm{t}(6 ; 14)$, are rarely found in AL $[15,18,52]$. $\mathrm{T}(14 ; 20)$ was reported to be associated with MAF-B expression in AL cell lines derived from a patient that eventually evolved into MM [52]. For $\mathrm{t}(6 ; 14)$, this may give rise to CCND3 dysregulation [13, 53]. In MM, $t(14 ; 20)$ is regarded as a high-risk factor while $\mathrm{t}(6 ; 14)$ is a standard-risk factor [13, 54]. However, there is still no evidence to support their prognostic roles in AL.

\section{Hyperdiploidy}

Hyperdiploidy is a well-recognized alternative pathogenetic pathway in plasma cell disorders. It is characterized by the presence of extra copies of multiple chromosomes, especially odd-numbered chromosome $3,5,7,9,11,15$, 19 and 21 [12, 55].

Because of the low percentage and low proliferative rate of plasma cells, conventional karyotypic analysis methods are not suitable for the study of ploidy in AL $[56,57]$. To overcome this problem, Wuilleme et al. established a definition of hyperdiploidy based on iFISH, which requires trisomies of at least 2 of 3 chromosome combinations to define hyperdiploidy [57]. According to this definition, about $30 \%$ and $50 \%$ of MGUS and MM respectively have hyperdiploidy, while the frequency of hyperdiploidy in $\mathrm{AL}$ is only about $10 \%[11,12,26,31,58]$. Hyperdiploidy is associated with intact immunoglobulin, $\mathrm{K}$ light chain restriction, older age, more plasma cell clones, lower CD38 expression level, and higher subclone formation frequency $[26,45,58]$. The prognostic effect of hyperdiploidy seems to be neutral in patients undergoing standard or high-dose melphalan therapies $[35,36]$, but an adverse outcome was detected in a study observing the effect of daratumumab-based therapy [30].

The application of Wuilleme's definition of hyperdiploidy will inevitably underestimate the prevalence of this genetic aberration. A study from Granzow et al. using high-density copy number arrays detected 25\% (29/118) of patients as hyperdiploidy, including six patients not identified as hyperdiploidy by Wuilleme's criteria [59]. Another study conducted by Ozga et al. described a broader definition of hyperdiploidy that included gains/ trisomies of 2 or more of any chromosome loci. In this study, $38 \%$ of patients harbored hyperdiploidy, which was confirmed to be associated with shorter PFS and OS in the multivariate analysis [17].

Overall, hyperdiploidy seems to confer a neutral or inferior outcome in AL patients, which is contradictory to results from MM studies that indicate a favorable prognostic effect of hyperdiploidy [12, 13, 60]. The transferability of the classically defined hyperdiploidy in the iFISH method, previously used in MM, to AL remains uncertain, and further studies are needed to define and validate the criteria of hyperdiploidy in AL based on the iFISH method.

\section{Trisomies}

Trisomies, defined as the presence of extra copies of one or more chromosomes, include both hyperdiploidy and mono-chromosome gains. $20-30 \%$ of AL patients harbor trisomies, with trisomies 9 being the most common genetic aberration, followed by trisomies $19,15,5,18,11$, 7, 3, 17, 4, 21 and 14 [15, 18, 59]. High dFLC (involved FLC minus uninvolved FLC) and bone marrow plasmacytosis are associated with the presence of trisomies [15]. In general, trisomies predict a worse outcome, especially in patients with plasma cell burden greater than $10 \%$ [11, 15]. This is different from the prognostic impact of trisomies in MM, where trisomies seem to attenuate prognostic risk [61, 62].

Reasons for the adverse impact of trisomies remain unknown. One of the possible reasons is that trisomies correlate with a higher clone evolution rate, indicating a more malignant potential of this disease. Moreover, the high dFLC level and plasma cell burden in patients with trisomies may lead to more amyloid fibril formation in targeted tissues and worsen organ functions. Further studies are still needed to explore the role of trisomies in AL. Besides, it might be necessary to subdivide trisomies into hyperdiploidy group, usually regarded as the primary cytogenetic event, and mono-chromosome gain group, regarded as the secondary cytogenetic event, as the underlying mechanisms of these two groups differ and they may have different prognostic impacts.

\section{Secondary genetic events}

Malignant plasma cells of an individual AL patient are not usually genetically identical, but harbor some additional aberrations, forming various subclones. This intraclonal heterogeneity in $\mathrm{AL}$ is the consequence of secondary cytogenetic events occurring during disease progression. Studies about AL's subclone architecture reveal that gain of 1q21, deletion of chromosome 13/13q, 17p and 8p21, secondary IgH translocations, and point mutations are frequent progression-related aberrations [26]. Hyperdiploidy is more often associated with subclone formation, but $t(11 ; 14)$ is less often [26]. Secondary genetic aberrations could induce additional activations of oncogenes and inactivations of tumor suppressor genes, promoting disease progression. Under the selective pressure of treatments, the outgrowth of drug-resistant clones may 
arise when intraclonal heterogeneity is present $[63,64]$. Hence, in general, the presence of secondary cytogenetic events in AL confers an unfavorable survival outcome.

\section{Gain of 1q21}

In $\mathrm{AL}, 1 \mathrm{q} 21$ gain usually results from the gain of the long arm of chromosome 1, rather than trisomies 1 [59]. $20-30 \%$ of AL patients harbor this genetic aberration, similar to the rate in MM $[15,35,59]$. However, in contrast to $M M$, in which the gain of $1 \mathrm{q}$ and loss of $1 \mathrm{p}$ always occur together [12,13], deletion of chromosome $1 \mathrm{p}$ is rarely found in AL. The presence of 1q21 gain is associated with plasmacytosis $[35,59]$, a tendency of progression to MM [31], a greater risk of cardiac involvement [65], lower CD38 expression level, and an inferior or neutral survival outcome [45]. Bochtler et al. also showed a close relationship between the gain of 1q21 and hyperdiploidy [58], but Granzow et al. implied that this might only be true when Wuilleme's definition of hyperdiploidy was used [59].

Probably, due to the low CD38 level, patients with 1q21 gain achieved less satisfactory outcomes than those without this genetic aberration when daratumumab-containing regimens were adopted $[30,66]$. One study investigating the impact of $1 \mathrm{q} 21$ on the standard melphalan/ dexamethasone treatment also demonstrates that $1 \mathrm{q} 21$ is an independent adverse prognostic factor for survival [35]. However, no significant prognostic impact of 1q21 has been identified in AL patients receiving bortezomibbased regimens or HDM + ASCT [33, 36].

The responsible genes underlying this chromosome aberration are unknown. The amplification of cyclin kinase subunit 1B (CKS1B) has been identified in a significant proportion of MM patients with the gain of 1q21 and is associated with an unfavorable survival outcome $[67,68]$, but data regarding the role of CKS1B in AL is laking. Granzow et al. reported a higher rate of concomitant loss of chromosome 14q ( $33 \%$ vs. $12 \%, \mathrm{p}<0.005)$ and $16 \mathrm{q}(24 \%$ vs. $1 \%, \mathrm{p}<0.001)$ in patients with the gain of 1q21 compared to those without this genetic aberration [59]. They suggested that two tumor suppressor genes $I D P 2$ and $M L H 3$, located in the minimal common region of deletions on chromosome 14q, may be responsible for the disease pathogenesis, but there is no evidence by now to validate this notion.

\section{Monosomy $13 /$ deletion of $13 q$}

Chromosome 13 abnormalities, including monosomy 13 and deletion of 13q (del13q), can be detected in about one-third of patients with AL $[15,18,25,59]$ and a half with MM $[69,70]$. The presence of del13q in MGUS is associated with a higher risk of progression to MM, while its prognostic effect in MM tends to be neutral [53]. In
$\mathrm{AL}$, monosomy $13 /$ del $13 \mathrm{q}$ are the only chromosome abnormalities identified so far to have cardiac tropism and are associated with high NT-proBNP level $[15,17$, 65]. They also correlate with plasmacytosis and a high dFLC level [15, 17]. However, no prognostic significance has been identified related to these genetic aberrations. Treatment modalities, including standard dose melphalan, HDM + HSCT, bortezomib-based, and daratumumab-based therapies, seem not to influence the survival outcome [30, 33, 35, 36]. Haploinsufficiency of $R b 1$ gene, located on chromosome 13q, has been proposed to be responsible for disease progression in MM [12, 71]. A similar effect may be present in $\mathrm{AL}$ and needs further exploration.

\section{Deletion of $17 p$}

Deletion of $17 \mathrm{p}$ (del17p), specifically at the locus of $17 \mathrm{p} 13$, occurs at a rate of no more than $5 \%$ in $\mathrm{AL}[15$, 26]. Probably due to its rareness, no significant prognostic impact of this genetic aberration has been reported to date in AL $[33,36]$. The largest-scale study about this genetic aberration in AL comes from a collaboration of seven countries involving 44 patients with del17p [72]. In this study, $95 \%$ of patients had cardiac involvement, and the median plasma cell burden was $22 \%$. Half of the patients could achieve a VGPR or CR, with two-thirds of them receiving bortezomib-based therapies. The median OS for this patient population was 49 months, which seems to be comparable to the general survival outcome of AL patients [10]. However, this study suggested that a higher burden of del17p may predict inferior survival outcomes because patients with $>50 \%$ del17p tended to live shorter than those with $\leq 50 \%$ del17p (median OS: 28 months vs. 52 months, $\mathrm{p}=0.08$ ).

Research about the pathogenetic effect of del17p in AL is scarce. Del17p can result in the deletion of an important tumor suppressor gene, $p 53$, the dysfunction of which leads to disease progression of various tumor kinds, including plasma cell disorders [73-75]. In MM, del17p is regarded as a strong adverse predictor of survival and is associated with a disposition to develop extramedullary disease [12, 13]. Several studies have demonstrated that the inactivation of p53 in MM may promote plasma cells to survive at extramedullary locations without undergoing apoptosis [76, 77]. A similar effect of the inactivation of p53 in AL may also occur, as two AL cell lines generated from a single person also have p53 loss, indicating that the absence of p53 may allow plasma cells to proliferate independently of the bone marrow environment [52]. 


\section{Other chromosome aberrations and driver mutations} Deletion of 8p21 and secondary IgH translocation occur at a low frequency in AL, so their clinical characteristics and prognostic effects are poorly understood [26, 31, 59], which highlights the need for multi-center cooperations to investigate specific genetic abnormalities of this rare disease. Trisomies 9 and 19 are the two most common chromosome gains in AL. A study involving 27 patients indicates that both of them are associated with an inferior PFS, but larger-scale studies are needed to confirm the result [65].

Whole exome sequencing (WES) can detect specific point mutations undetectable by the conventional iFISH method. A series of recurrent mutations in AL have been identified, but they all occur at a very low rate and there is no consistent result regarding these recurrent mutations in recent studies [65, 78-80]. A research based on WES and targeted gene sequencing reported that three recurrent mutations on ASB15, ASCC3 and HIST1H1E are associated with inferior OS [80], but other studies were unable to identify any linkage between genetic mutations and patients' outcomes $[65,78,79]$. In terms of MM related driver genes in AL, they are present at a frequency similar to that in MGUS, which is lower than in MM $[65,79]$. KRAS and NRAS activated mutations, commonly found in MM, are only identified in a few cases in $\operatorname{AL}[65,78,79]$, but one study identified mutation on KRAS as a recurrent mutation without survival significance [80].

\section{Genomic alterations related to amyloid formation}

The cytogenetic landscape of $\mathrm{AL}$ displays profound similarity with that of MGUS and MM, confirming the concept that they are related plasma cell dyscrasia. However, these findings are insufficient to explain why plasma cells in AL are more prone to secret amyloid-generating proteins. Fortunately, research on the immunoglobulin light chains (IgL) helps shed some

Table 2 Organ tropism of AL amyloidosis related to lgL germline genes

\begin{tabular}{|c|c|c|c|}
\hline $\begin{array}{l}\text { Light chain } \\
\text { germline gene }\end{array}$ & $\begin{array}{l}\text { Prevalence in AL (\%) } \\
{[28,87,88]}\end{array}$ & Organ tropism & Other associated features \\
\hline \multirow[t]{3}{*}{ k light chain } & $\sim 20$ & $\uparrow$ Hepatic involvement $[28,79,87,90]$ & Better survival outcome after ASCT [90] \\
\hline & & $\uparrow$ Soft tissue involvement [85] & \\
\hline & & $\uparrow$ Bone involvement [85] & \\
\hline \multirow[t]{2}{*}{ IGKV1-05 } & 2 & May $\downarrow$ renal involvement [87] & Inferior overall survival [87] \\
\hline & & May $\uparrow$ advanced cardiac disease [87] & \\
\hline \multirow[t]{2}{*}{ IGKV1-33 } & 5 & $\uparrow$ Hepatic involvement [87] & High circulating dFLC [87] \\
\hline & & May $\downarrow$ peripheral nerve involvement [87] & \\
\hline IGKV3-20 & 2 & Localized AL amyloidosis [87] & - \\
\hline \multirow[t]{2}{*}{ IGKV4-01 } & 5 & $\uparrow$ Gastrointestinal involvement [88] & \\
\hline & & $\uparrow$ Soft tissue involvement [88] & \\
\hline$\lambda$ light chain & $\sim 80$ & & \\
\hline \multirow[t]{3}{*}{ IGLVI-44 } & 6 & $\uparrow$ Cardiac involvement $[81,82,86,87]$ & $\downarrow$ Rate of trisomies [87] \\
\hline & & May $\uparrow$ multisystem involvement $[81,82]$ & \\
\hline & & $\downarrow$ Hepatic involvement [88] & \\
\hline IGLV2-08 & 3 & $\uparrow$ Lung involvement [88] & Associated with lgM light chain amyloidosis [88] \\
\hline \multirow[t]{4}{*}{ IGLV2-14 } & 9 & $\uparrow$ Gastrointestinal localized AL [87] & $\uparrow$ Intact immunoglobulin [87] \\
\hline & & May $\uparrow$ cardiac involvement [82] & $\downarrow$ Circulating dFLC $[87,88]$ \\
\hline & & $\begin{array}{l}\text { May } \uparrow \text { peripheral nerve involvement [87], but } \\
\text { another study did not support this finding [88] }\end{array}$ & Associated with lgM light chain amyloidosis [88] \\
\hline & & May $\uparrow$ multisystem involvement [82] & \\
\hline \multirow[t]{4}{*}{ IGLV3-01 } & 9 & May $\uparrow$ cardiac involvement [82] & - \\
\hline & & May $\uparrow$ multisystem involvement $[82,84]$ & \\
\hline & & May $\downarrow$ advaced cardiac disease $[86,87]$ & \\
\hline & & May $\downarrow$ renal involvement [87] & \\
\hline IGLV3-19 & 2 & May $\uparrow$ cardiac involvement [87] & \\
\hline IGLV3-21 & 5 & $\downarrow$ Renal involvement [87] & $\uparrow$ Rate of monosomy 13q [87] \\
\hline \multirow[t]{3}{*}{ IGLV6-57 } & 13 & $\uparrow$ Renal involvement $[81,82,84,87,88]$ & $\uparrow$ Rate of $\mathrm{t}(11 ; 14)[87]$ \\
\hline & & May $\downarrow$ cardiac involvement $[14,86]$ & $\downarrow$ Rate of trisomies [87] \\
\hline & & & Better survival outcome after ASCT [81] \\
\hline
\end{tabular}

The contents highlighted in bold indicate that they are supported by 2 or more evidenceswith statistical significance 


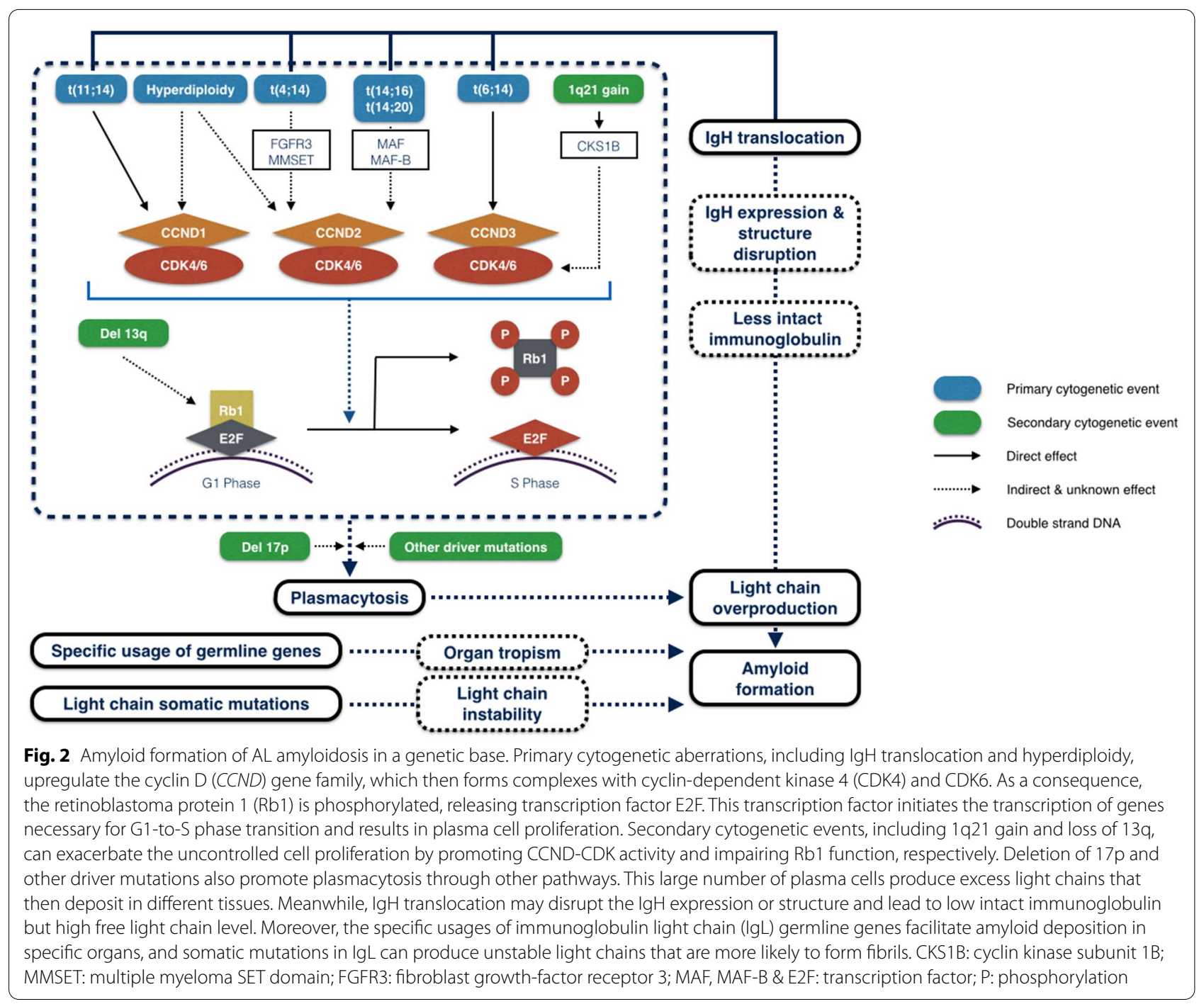

light on the pathogenesis of this disease. Data in the previous studies indicate that organ tropism in AL may be the function of the usage of specific IgL germline genes [81-88] (see Table 2). For example, AL patients with $\mathrm{k}$ light chain have more liver involvement $[28,87$, $89,90]$. On the other hand, the germline genes IGLV657 and IGLV1-44 are linked to increased renal and cardiac involvement, respectively [81, 82, 84, 86-88]. Besides, there is an overrepresentation of specific germline genes in $\mathrm{AL}$, that is, some germline genes, such as IGLV6-57, IGLV3-01 and IGLV2-14, occur at a higher frequency in $\mathrm{AL}$ than other plasma cell dyscrasia or normal B cells $[81,87,88,91]$.

Somatic mutations in the $\operatorname{IgL}$ genes, generated in the process of immunoglobulin synthesis, add complexity to the IgL structure. The burden of the somatic mutations and the specific site that a mutation occurs can influence the stability and amyloidogenicity of IgL [91-95]. A model from a recent study based on somatic mutations in IgL displays high sensitivity and specificity to predict the free light chain toxicity [96]. Moreover, the introduction of specific point mutations in the IgL locus could attenuate the free light chain toxicity [96-98], which underlines the possibility of gene therapy in AL.

Altogether, these findings indicate that the formation of amyloid fibril in various organs is a multifactorial process involving chromosome aberrations, secondary mutations, specific usage of IgL germline genes, IgL somatic mutations, and some other unidentified reasons (see Fig. 2).

\section{Conclusions}

AL amyloidosis is a plasma cell disorder having distinct features from that of MM, although they indeed share some genetic similarities. Each genetic aberration in AL involves distinct pathogenetic pathways and displays 
some special clinical features. However, these are insufficient to explain the most significant feature of AL, the amyloid formation. Studies about the IgL indicate that specific usages of IgL germline genes and point mutations in the IgL locus may be capable of predicting the organ tropism and fibril formation tendency of this disease. Treatment options based on the cytogenetic features of $\mathrm{AL}$ and novel therapies targeting amyloid formation have a promising future. To date, due to the low incidence of $\mathrm{AL}$, most studies of this disease are retrospective. Therefore, multi-center cooperations are needed to investigate specific cytogenetic abnormalities and conduct sizable clinical trials in this disease. The development of the predictive model, based on the cytogenetic properties of AL, may help improve the early diagnosis and clinical outcomes in AL patients.

\begin{abstract}
Abbreviations
AL: Immunoglobulin light chain amyloidosis; FLC: Free immunoglobulin light chain; MGUS: Monoclonal gammopathy of undetermined significance; MM: Multiple myeloma; IgH: Immunoglobulin heavy chain; iFISH: Interphase-

fluorescence in situ hybridization; PFS: Progression-free survival; OS: Overall survival; CCND1: Cyclin D1; HDM: High-dose melphalan; ASCT: Autologous stem cell transplantation; hemEFS: Hematological event-free survival; FGFR3: Fibroblast growth factor receptor 3; MMSET: Multiple myeloma SET domain; CKS1B: Cyclin kinase subunit 1B; WES: Whole exome sequencing; IgL: Immunoglobulin light chain.
\end{abstract}

\section{Acknowledgements}

None.

\section{Authors' contributions}

$L X$ wrote the paper and created the tables and the figures. YS designed and reviewed the paper. Both authors read and approved the final manuscript.

\section{Funding}

None.

\section{Availability of data and materials}

Not applicable.

\section{Declarations}

Ethics approval and consent to participate

Not applicable.

\section{Consent for publication}

Not applicable.

\section{Competing interests}

The authors declare no competing interests.

\begin{abstract}
Author details
'Shantou University Medical College, Shantou 515031, Guangdong, China. ${ }^{2}$ The First Affiliated Hospital of Shantou University Medical College, Shantou 515041, Guangdong, China. ${ }^{3}$ Department of Hematology, The First Affiliated Hospital of Shantou University Medical College, Shantou 515041, Guangdong, China.
\end{abstract}

Received: 3 May 2021 Accepted: 11 July 2021

Published online: 20 July 2021

\section{References}

1. Merlini G, Dispenzieri A, Sanchorawala V, Schönland SO, Palladini G, Hawkins PN, et al. Systemic immunoglobulin light chain amyloidosis. Nat Rev Dis Primers. 2018;4(1):38.

2. Hemminki K, Li X, Försti A, Sundquist J, Sundquist K. Incidence and survival in non-hereditary amyloidosis in Sweden. BMC Public Health. 2012;12:974.

3. Pinney JH, Smith CJ, Taube JB, Lachmann HJ, Venner CP, Gibbs SD, et al. Systemic amyloidosis in England: an epidemiological study. Br J Haematol. 2013;161(4):525-32.

4. QuockTP, Yan T, Chang E, Guthrie S, Broder MS. Healthcare resource utilization and costs in amyloid light-chain amyloidosis: a real-world study using US claims data. J Comp Eff Res. 2018;7(6):549-59.

5. Merlini G, Wechalekar AD, Palladini G. Systemic light chain amyloidosis: an update for treating physicians. Blood. 2013;121(26):5124-30.

6. Li T, Huang X, Cheng S, Zhao L, Ren G, Chen W, et al. Utility of abdominal skin plus subcutaneous fat and rectal mucosal biopsy in the diagnosis of AL amyloidosis with renal involvement. PLoS ONE. 2017;12(9):e0185078.

7. Tian L, Tang A, Zhang X, Mei Z, Liu F, Li J, et al. Incomplete ileus and hemafecia as the presenting features of multi-organ involved primary systemic AL amyloidosis: a rare case report. BMC Gastroenterol. 2017;17(1):72.

8. Palladini G, Barassi A, Klersy C, Pacciolla R, Milani P, Sarais G, et al. The combination of high-sensitivity cardiac troponin T (hs-cTnT) at presentation and changes in N-terminal natriuretic peptide type B (NT-proBNP) after chemotherapy best predicts survival in AL amyloidosis. Blood. 2010;116(18):3426-30.

9. Merlini G, Stone MJ. Dangerous small B-cell clones. Blood. 2006;108(8):2520-30.

10. Muchtar E, Gertz MA, Kumar SK, Lacy MQ, Dingli D, Buadi FK, et al. Improved outcomes for newly diagnosed AL amyloidosis between 2000 and 2014: cracking the glass ceiling of early death. Blood. 2017;129(15):2111-9.

11. Muchtar E, Gertz MA, Lacy MQ, Go RS, Buadi FK, Dingli D, et al. Ten-year survivors in AL amyloidosis: characteristics and treatment pattern. $\mathrm{Br} J$ Haematol. 2019;187(5):588-94.

12. Fonseca R, Bergsagel PL, Drach J, Shaughnessy J, Gutierrez N, Stewart AK, et al. International Myeloma Working Group molecular classification of multiple myeloma: spotlight review. Leukemia. 2009;23(12):2210-21.

13. Chesi M, Bergsagel PL. Molecular pathogenesis of multiple myeloma: basic and clinical updates. Int J Hematol. 2013;97(3):313-23.

14. Maura F, Bolli N, Angelopoulos N, Dawson KJ, Leongamornlert D, Martincorena l, et al. Genomic landscape and chronological reconstruction of driver events in multiple myeloma. Nat Commun. 2019;10(1):3835.

15. Warsame R, Kumar SK, Gertz MA, Lacy MQ, Buadi FK, Hayman SR, et al. Abnormal FISH in patients with immunoglobulin light chain amyloidosis is a risk factor for cardiac involvement and for death. Blood Cancer $\mathrm{J}$. 2015;5(5):e310.

16. Hammons L, Brazauskas R, Pasquini M, Hamadani M, Hari P, D'Souza A. Presence of fluorescent in situ hybridization abnormalities is associated with plasma cell burden in light chain amyloidosis. Hematol Oncol Stem Cell Ther. 2018;11(2):105-11.

17. Ozga M, Zhao Q, Benson D Jr, Elder P, Williams N, Bumma N, et al. AL amyloidosis: the effect of fluorescent in situ hybridization abnormalities on organ involvement and survival. Cancer Med. 2020;10:965-73.

18. Muchtar E, Dispenzieri A, Kumar SK, Ketterling RP, Dingli D, Lacy MQ, et al. Interphase fluorescence in situ hybridization in untreated AL amyloidosis has an independent prognostic impact by abnormality type and treatment category. Leukemia. 2017;31(7):1562-9.

19. Kim SY, Im K, Park SN, Kim JA, Yoon SS, Lee DS. Burden of cytogenetically abnormal plasma cells in light chain amyloidosis and their prognostic relevance. Leuk Res. 2016:44:45-52.

20. Bergsagel PL, KuehI WM. Molecular pathogenesis and a consequent classification of multiple myeloma. J Clin Oncol. 2005;23(26):6333-8.

21. Deshmukh M, Elderfield K, Rahemtulla A, Naresh KN. Immunophenotype of neoplastic plasma cells in AL amyloidosis. J Clin Pathol. 2009;62(8):724-30.

22. Lee JC, Wu H, Prokaeva TB, O'Hara C, Seldin DC. Expression of D-type cyclins in AL amyloidosis plasma cells. J Clin Pathol. 2012;65(11):1052-5.

23. da Silva Filho MI, Försti A, Weinhold N, Meziane I, Campo C, Huhn S, et al. Genome-wide association study of immunoglobulin light chain 
amyloidosis in three patient cohorts: comparison with myeloma. Leukemia. 2017;31(8):1735-42.

24. Palumbo A, Avet-Loiseau H, Oliva S, Lokhorst HM, Goldschmidt H, Rosinol $L$, et al. Revised international staging system for multiple myeloma: a report from International Myeloma Working Group. J Clin Oncol. 2015;33(26):2863-9.

25. Harrison CJ, Mazzullo H, Ross FM, Cheung KL, Gerrard G, Harewood $L$, et al. Translocations of $14 q 32$ and deletions of $13 q 14$ are common chromosomal abnormalities in systemic amyloidosis. Br J Haematol. 2002;117(2):427-35.

26. Bochtler T, Merz M, Hielscher T, Granzow M, Hoffmann K, Krämer A, et al. Cytogenetic intraclonal heterogeneity of plasma cell dyscrasia in AL amyloidosis as compared with multiple myeloma. Blood Adv. 2018;2(20):2607-18.

27. Bryce AH, Ketterling RP, Gertz MA, Lacy M, Knudson RA, Zeldenrust S, et al. Translocation $\mathrm{t}(11 ; 14)$ and survival of patients with light chain (AL) amyloidosis. Haematologica. 2009;94(3):380-6.

28. Kumar S, Dispenzieri A, Katzmann JA, Larson DR, Colby CL, Lacy MQ, et al. Serum immunoglobulin free light-chain measurement in primary amyloidosis: prognostic value and correlations with clinical features. Blood. 2010;116(24):5126-9.

29. Kumar S, Zhang L, Dispenzieri A, Van Wier S, Katzmann JA, Snyder M, et al. Relationship between elevated immunoglobulin free light chain and the presence of $\mathrm{IgH}$ translocations in multiple myeloma. Leukemia. 2010;24(8):1498-505.

30. Kimmich CR, Terzer T, Benner A, Dittrich T, Veelken K, Carpinteiro A, et al. Daratumumab for systemic AL amyloidosis: prognostic factors and adverse outcome with nephrotic-range albuminuria. Blood. 2020;135(18):1517-30

31. Bochtler T, Hegenbart U, Cremer FW, Heiss C, Benner A, Hose D, et al. Evaluation of the cytogenetic aberration pattern in amyloid light chain amyloidosis as compared with monoclonal gammopathy of undetermined significance reveals common pathways of karyotypic instability. Blood. 2008;111(9):4700-5.

32. Zhou P, Hoffman J, Landau H, Hassoun H, Iyer L, Comenzo RL. Clonal plasma cell pathophysiology and clinical features of disease are linked to clonal plasma cell expression of cyclin D1 in systemic light-chain amyloidosis. Clin Lymphoma Myeloma Leuk. 2012;12(1):49-58.

33. Bochtler T, Hegenbart U, Kunz C, Granzow M, Benner A, Seckinger A, et al. Translocation $\mathrm{t}(11 ; 14)$ is associated with adverse outcome in patients with newly diagnosed AL amyloidosis when treated with bortezomibbased regimens. J Clin Oncol. 2015;33(12):1371-8.

34. Dumas B, Yameen H, Sarosiek S, Sloan JM, Sanchorawala V. Presence of $\mathrm{t}(11 ; 14)$ in $\mathrm{AL}$ amyloidosis as a marker of response when treated with a bortezomib-based regimen. Amyloid Int J Exp Clin Investig. 2020:27(4):244-9.

35. Bochtler T, Hegenbart U, Kunz C, Benner A, Seckinger A, Dietrich S, et al. Gain of chromosome 1q21 is an independent adverse prognostic factor in light chain amyloidosis patients treated with melphalan/dexamethasone. Amyloid Int J Exp Clin Investig. 2014;21(1):9-17.

36. Bochtler T, Hegenbart U, Kunz C, Benner A, Kimmich C, Seckinger A, et al. Prognostic impact of cytogenetic aberrations in AL amyloidosis patients after high-dose melphalan: a long-term follow-up study. Blood. 2016;128(4):594-602.

37. Kumar S, Kaufman JL, Gasparetto C, Mikhael J, Vij R, Pegourie B, et al, Efficacy of venetoclax as targeted therapy for relapsed/refractory $\mathrm{t}(11 ; 14)$ multiple myeloma. Blood. 2017;130(22):2401-9.

38. Touzeau C, Le Gouill S, Mahé B, Boudreault JS, Gastinne T, Blin N, et al. Deep and sustained response after venetoclax therapy in a patient with very advanced refractory myeloma with translocation $\mathrm{t}(11 ; 14)$. Haematologica. 2017;102(3):e112-4.

39. Paner A, Patel P, Dhakal B. The evolving role of translocation $\mathrm{t}(11 ; 14)$ in the biology, prognosis, and management of multiple myeloma. Blood Rev. 2020:41:100643.

40. Leung N, Thome SD, Dispenzieri A. Venetoclax induced a complete response in a patient with immunoglobulin light chain amyloidosis plateaued on cyclophosphamide, bortezomib and dexamethasone. Haematologica. 2018;103(3):e135-7.

41. Ghilardi G, Stussi G, Mazzucchelli L, Röcken C, Rossi D, Gerber B. Venetoclax plus daratumumab induce hematological $C R$ and organ response in an AL amyloidosis patient with t(11;14). Amyloid Int J Exp Clin Investig. 2019;26(3):173-4.

42. Premkumar V, Comenzo R, Lentzsch S. Venetoclax in immunoglobulin light chain amyloidosis: is this the beginning or the end? Clin Lymphoma Myeloma Leuk. 2019;19(10):686-8.

43. Sidiqi MH, Al Saleh AS, Leung N, Jevremovic D, Aljama MA, Gonsalves WI, et al. Venetoclax for the treatment of translocation $(11 ; 14)$ AL amyloidosis. Blood Cancer J. 2020;10(5):55.

44. Premkumar VJ, Lentzsch S, Pan S, Bhutani D, Richter J, Jagannath S, et al. Venetoclax induces deep hematologic remissions in $\mathrm{t}(11 ; 14)$ relapsed/ refractory AL amyloidosis. Blood Cancer J. 2021;1 1(1):10.

45. Seckinger A, Hillengass J, Emde M, Beck S, Kimmich C, Dittrich T, et al. CD38 as immunotherapeutic target in light chain amyloidosis and multiple myeloma-association with molecular entities, risk, survival, and mechanisms of upfront resistance. Front Immunol. 2018;9:1676.

46. Kriegsmann K, Dittrich T, Neuber B, Awwad MHS, Hegenbart U, Goldschmidt $H$, et al. Quantification of number of CD38 sites on bone marrow plasma cells in patients with light chain amyloidosis and smoldering multiple myeloma. Cytom B Clin Cytom. 2018;94(5):611-20.

47. Chesi M, Nardini E, Brents LA, Schröck E, Ried T, Kuehl WM, et al. Frequent translocation $\mathrm{t}(4 ; 14)(\mathrm{p} 16.3 ; \mathrm{q} 32.3)$ in multiple myeloma is associated with increased expression and activating mutations of fibroblast growth factor receptor 3. Nat Genet. 1997;16(3):260-4.

48. Chesi M, Nardini E, Lim RS, Smith KD, KuehI WM, Bergsagel PL. The $\mathrm{t}(4 ; 14)$ translocation in myeloma dysregulates both FGFR3 and a novel gene, MMSET, resulting in IgH/MMSET hybrid transcripts. Blood. 1998:92(9):3025-34.

49. Martinez-Garcia E, Popovic R, Min DJ, Sweet SM, Thomas PM, Zamdborg $L$, et al. The MMSET histone methyl transferase switches global histone methylation and alters gene expression in $\mathrm{t}(4 ; 14)$ multiple myeloma cells. Blood. 2011;117(1):211-20.

50. Malgeri U, Baldini L, Perfetti V, Fabris S, Vignarelli MC, Colombo G, et al. Detection of $\mathrm{t}(4 ; 14)(\mathrm{p} 16.3 ; \mathrm{q} 32)$ chromosomal translocation in multiple myeloma by reverse transcription-polymerase chain reaction analysis of IGH-MMSET fusion transcripts. Cancer Res. 2000;60(15):4058-61.

51. Perfetti V, Coluccia AM, Intini D, Malgeri U, Vignarelli MC, Casarini S, et al. Translocation $T(4 ; 14)(p 16.3 ; q 32)$ is a recurrent genetic lesion in primary amyloidosis. Am J Pathol. 2001;158(5):1599-603.

52. Arendt BK, Ramirez-Alvarado M, Sikkink LA, Keats JJ, Ahmann GJ, Dispenzieri A, et al. Biologic and genetic characterization of the novel amyloidogenic lambda light chain-secreting human cell lines, ALMC-1 and ALMC-2. Blood. 2008;112(5):1931-41.

53. Neuse CJ, Lomas OC, Schliemann C, Shen YJ, Manier S, Bustoros M, et al. Genome instability in multiple myeloma. Leukemia. 2020;34(11):2887-97.

54. Mikhael JR, Dingli D, Roy V, Reeder CB, Buadi FK, Hayman SR, et al. Management of newly diagnosed symptomatic multiple myeloma: updated Mayo Stratification of Myeloma and Risk-Adapted Therapy (mSMART) consensus guidelines 2013. Mayo Clin Proc. 2013;88(4):360-76.

55. Carrasco DR, Tonon G, Huang Y, Zhang Y, Sinha R, Feng B, et al. High-resolution genomic profiles define distinct clinico-pathogenetic subgroups of multiple myeloma patients. Cancer Cell. 2006;9(4):313-25.

56. Chng WJ, Van Wier SA, Ahmann GJ, Winkler JM, Jalal SM, Bergsagel PL, et al. A validated FISH trisomy index demonstrates the hyperdiploid and nonhyperdiploid dichotomy in MGUS. Blood. 2005;106(6):2156-61.

57. Wuilleme S, Robillard N, Lodé L, Magrangeas F, Beris H, Harousseau JL, et al. Ploidy, as detected by fluorescence in situ hybridization, defines different subgroups in multiple myeloma. Leukemia. 2005;19(2):275-8.

58. Bochtler T, Hegenbart U, Heiss C, Benner A, Moos M, Seckinger A, et al. Hyperdiploidy is less frequent in AL amyloidosis compared with monoclonal gammopathy of undetermined significance and inversely associated with translocation t(11;14). Blood. 2011;117(14):3809-15.

59. Granzow M, Hegenbart U, Hinderhofer K, Hose D, Seckinger A, Bochtler $T$, et al. Novel recurrent chromosomal aberrations detected in clonal plasma cells of light chain amyloidosis patients show potential adverse prognostic effect: first results from a genome-wide copy number array analysis. Haematologica. 2017:102(7):1281-90.

60. Mei J, Zhai Y, Li H, Li F, Zhou X, Song P, et al. Prognostic impact of hyperdiploidy in multiple myeloma patients with high-risk cytogenetics: a pilot study in China. J Cancer Res Clin Oncol. 2018;144(11):2263-73. 
61. Kumar S, Fonseca R, Ketterling RP, Dispenzieri A, Lacy MQ, Gertz MA, et al. Trisomies in multiple myeloma: impact on survival in patients with highrisk cytogenetics. Blood. 2012;119(9):2100-5.

62. Chretien ML, Corre J, Lauwers-Cances V, Magrangeas F, Cleynen A, Yon $\mathrm{E}$, et al. Understanding the role of hyperdiploidy in myeloma prognosis: which trisomies really matter? Blood. 2015;126(25):2713-9.

63. Egan JB, Shi CX, Tembe W, Christoforides A, Kurdoglu A, Sinari S, et al. Whole-genome sequencing of multiple myeloma from diagnosis to plasma cell leukemia reveals genomic initiating events, evolution, and clonal tides. Blood. 2012;120(5):1060-6.

64. Keats JJ, Chesi M, Egan JB, Garbitt VM, Palmer SE, Braggio E, et al. Clonal competition with alternating dominance in multiple myeloma. Blood. 2012;120(5):1067-76.

65. Cuenca I, Alameda D, Sanchez-Vega B, Gomez-Sanchez D, Alignani D, Lasa M, et al. Immunogenetic characterization of clonal plasma cells in systemic light-chain amyloidosis. Leukemia. 2021;35(1):245-9.

66. Kimmich CR, Terzer T, Benner A, Hansen T, Carpinteiro A, Dittrich T, et al. DaraRD in systemic AL amyloidosis: high efficacy, relevant toxicity and main adverse effect of gain 1q21. Am J Hematol. 2021;96(7):E253-7.

67. Fonseca R, Van Wier SA, Chng WJ, Ketterling R, Lacy MQ, Dispenzieri A, et al. Prognostic value of chromosome 1q21 gain by fluorescent in situ hybridization and increase CKS1B expression in myeloma. Leukemia. 2006;20(11):2034-40.

68. Chen MH, Qi C, Reece D, Chang H. Cyclin kinase subunit 1B nuclear expression predicts an adverse outcome for patients with relapsed/ refractory multiple myeloma treated with bortezomib. Hum Pathol. 2012;43(6):858-64.

69. Fonseca R, Oken MM, Harrington D, Bailey RJ, Van Wier SA, Henderson $\mathrm{KJ}$, et al. Deletions of chromosome 13 in multiple myeloma identified by interphase FISH usually denote large deletions of the q arm or monosomy. Leukemia. 2001;15(6):981-6.

70. Walker BA, Leone PE, Chiecchio L, Dickens NJ, Jenner MW, Boyd KD, et al. A compendium of myeloma-associated chromosomal copy number abnormalities and their prognostic value. Blood. 2010;116(15):e56-65.

71. Chavan SS, He J, Tytarenko R, Deshpande S, Patel P, Bailey M, et al. Bi-allelic inactivation is more prevalent at relapse in multiple myeloma, identifying RB1 as an independent prognostic marker. Blood Cancer J. 2017;7(2):e535

72. Wong SW, Hegenbart U, Palladini G, Shah GL, Landau HJ, Warner M, et al. Outcome of patients with newly diagnosed systemic light-chain amyloidosis associated with deletion of 17p. Clin Lymphoma Myeloma Leuk. 2018;18(11):e493-9.

73. Parrales A, Iwakuma T. Targeting oncogenic mutant p53 for cancer therapy. Front Oncol. 2015;5:288.

74. Flynt E, Bisht K, Sridharan V, Ortiz M, Towfic F, Thakurta A. Prognosis, biology, and targeting of TP53 dysregulation in multiple myeloma. Cells. 2020;9(2):287

75. Rajkumar SV. Multiple myeloma: 2020 update on diagnosis, risk-stratification and management. Am J Hematol. 2020;95(5):548-67.

76. Tiedemann RE, Gonzalez-Paz N, Kyle RA, Santana-Davila R, Price-Troska T, Van Wier SA, et al. Genetic aberrations and survival in plasma cell leukemia. Leukemia. 2008;22(5):1044-52.

77. Xiong W, Wu X, Starnes S, Johnson SK, Haessler J, Wang S, et al. An analysis of the clinical and biologic significance of TP53 loss and the identification of potential novel transcriptional targets of TP53 in multiple myeloma. Blood. 2008;112(10):4235-46.

78. Paiva B, Martinez-Lopez J, Corchete LA, Sanchez-Vega B, Rapado I, Puig N, et al. Phenotypic, transcriptomic, and genomic features of clonal plasma cells in light-chain amyloidosis. Blood. 2016;127(24):3035-9.

79. Boyle EM, Ashby C, Wardell CP, Rowczenio D, Sachchithanantham S, Wang $Y$, et al. The genomic landscape of plasma cells in systemic light chain amyloidosis. Blood. 2018;132(26):2775-7.

80. Huang XF, Jian S, Lu JL, Shen KN, Feng J, Zhang CL, et al. Genomic profiling in amyloid light-chain amyloidosis reveals mutation profiles associated with overall survival. Amyloid Int J Exp Clin Investig. 2020:27(1):36-44.

81. Comenzo RL, Wally J, Kica G, Murray J, Ericsson T, Skinner M, et al. Clonal immunoglobulin light chain variable region germline gene use in $\mathrm{AL}$ amyloidosis: association with dominant amyloid-related organ involvement and survival after stem cell transplantation. Br J Haematol. 1999;106(3):744-51.

82. Comenzo RL, Zhang Y, Martinez C, Osman K, Herrera GA. The tropism of organ involvement in primary systemic amyloidosis: contributions of $\mathrm{g} \mathrm{V}(\mathrm{L})$ germ line gene use and clonal plasma cell burden. Blood. 2001;98(3):714-20.

83. Perfetti V, Casarini S, Palladini G, Vignarelli MC, Klersy C, Diegoli M, et al. Analysis of V(lambda)-J(lambda) expression in plasma cells from primary $(\mathrm{AL})$ amyloidosis and normal bone marrow identifies $3 r$ (lambdallI) as a new amyloid-associated germline gene segment. Blood. 2002;100(3):948-53.

84. Abraham RS, Geyer SM, Price-Troska TL, Allmer C, Kyle RA, Gertz MA, et al. Immunoglobulin light chain variable $(V)$ region genes influence clinical presentation and outcome in light chain-associated amyloidosis (AL). Blood. 2003;101(10):3801-8.

85. Prokaeva T, Spencer B, Kaut M, Ozonoff A, Doros G, Connors LH, et al. Soft tissue, joint, and bone manifestations of AL amyloidosis: clinical presentation, molecular features, and survival. Arthritis Rheum. 2007;56(11):3858-68.

86. Perfetti V, Palladini G, Casarini S, Navazza V, Rognoni P, Obici L, et al. The repertoire of $\lambda$ light chains causing predominant amyloid heart involvement and identification of a preferentially involved germline gene, IGLV144. Blood. 2012;119(1):144-50.

87. Kourelis TV, Dasari S, Theis JD, Ramirez-Alvarado M, Kurtin PJ, Gertz MA, et al. Clarifying immunoglobulin gene usage in systemic and localized immunoglobulin light-chain amyloidosis by mass spectrometry. Blood. 2017;129(3):299-306

88. Sidana S, Dasari S, Kourelis TV, Dispenzieri A, Murray DL, King RL, et al. IGVL gene region usage correlates with distinct clinical presentation in IgM vs non-lgM light chain amyloidosis. Blood Adv. 2021;5(8):2101-5.

89. Russo P, Palladini G, Foli A, Zenone Bragotti L, Milani P, Nuvolone M, et al. Liver involvement as the hallmark of aggressive disease in light chain amyloidosis: distinctive clinical features and role of light chain type in 225 patients. Amyloid Int J Exp Clin Investig. 2011;18(Suppl 1):92-3.

90. Sidiqi MH, Aljama MA, Muchtar E, Buadi FK, Warsame R, Lacy MQ, et al. Light chain type predicts organ involvement and survival in AL amyloidosis patients receiving stem cell transplantation. Blood Adv. 2018;2(7):769-76.

91. Ramirez-Alvarado M. Amyloid formation in light chain amyloidosis. Curr Top Med Chem. 2012;12(22):2523-33.

92. Enqvist S, Sletten K, Stevens FJ, Hellman U, Westermark P. Germ line origin and somatic mutations determine the target tissues in systemic AL-amyloidosis. PLoS ONE. 2007;2(10):e981.

93. Poshusta TL, Sikkink LA, Leung N, Clark RJ, Dispenzieri A, RamirezAlvarado M. Mutations in specific structural regions of immunoglobulin light chains are associated with free light chain levels in patients with $A L$ amyloidosis. PLoS ONE. 2009;4(4):e5169.

94. Morgan GJ, Kelly JW. The kinetic stability of a full-length antibody light chain dimer determines whether endoproteolysis can release amyloidogenic variable domains. J Mol Biol. 2016;428(21):4280-97.

95. Rottenaicher GJ, Weber B, RührnößI F, Kazman P, Absmeier RM, Hitzenberger M, et al. Molecular mechanism of amyloidogenic mutations in hypervariable regions of antibody light chains. J Biol Chem. 2021;296:100334

96. Garofalo M, Piccoli L, Romeo M, Barzago MM, Ravasio S, Foglierini M, et al. Machine learning analyses of antibody somatic mutations predict immunoglobulin light chain toxicity. Nat Commun. 2021;12(1):3532.

97. Luna-Martínez OD, Hernández-Santoyo A, Villalba-Velázquez MI, SánchezAlcalá R, Fernández-Velasco DA, Becerril B. Stabilizing an amyloidogenic $\lambda 6$ light chain variable domain. FEBS J. 2017;284(21):3702-17.

98. Maritan M, Ambrosetti A, Oberti L, Barbiroli A, Diomede L, Romeo M, et al. Modulating the cardiotoxic behaviour of immunoglobulin light chain dimers through point mutations. Amyloid Int J Exp Clin Investig. 2019;26(sup1):105-6.

\section{Publisher's Note}

Springer Nature remains neutral with regard to jurisdictional claims in published maps and institutional affiliations. 